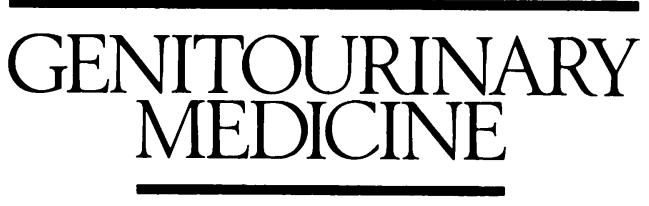

Editorial

\title{
Time for a Change
}

When I became the editor of Genitourinary Medicine early in 1989 , I set out five objectives which I hoped to achieve during my term, including, "to broaden the base and the appeal of Genitourinary Medicine by attracting more articles on the behavioural, epidemiological, social and historical aspects of sexually transmitted diseases . . . and the viral infections (with herpes simplex virus, human papillomavirus, hepatitis $B$ virus, and the human immunodeficiency virus) while still maintaining a sizeable interest in the traditional sexual infections; to establish a 'fast lane' for rapid publication of articles of particular interest; to commission regular . . . review articles on subjects of current interest or concern; to speed up the time for reviewing and publishing papers; and to stimulate a dynamic correspondence section".

Some of these objectives have been achieved, in other areas I have been less successful. Successes include a dynamic correspondence section (in 1994 we published 21 letters and 15 items in matters arising) and the publication of regular review articles including a series on Laboratory Methods in Genitourinary Medicine, an innovative series on STDs in Children edited by Dr Greta Forster, a novel series of HIV clinicopathological conferences edited by Dr Rob Miller and Dr Sebastian Lucas, an ongoing (albeit intermittent) series on the Pathogenesis of STDs and HIV Related Problems and a number of acclaimed historical reviews including Eminent Venereologists by Dr David Oriel and a collection on the History of STDs edited by Milton Lewis and Dr Michael Waugh.

The objective of broadening the base of the journal has been partially successful. Manuscripts dealing with HIV/AIDS and human papillomavirus were the commonest subjects between 1991 and 1994, with the majority of the articles dealing with the clinical, therapeutic and epidemiological aspects of STDs. However, the journal still receives and publishes very few articles addressing the behavioural and social aspects sexual health.

I believe that in most circumstances the speed of reviewing and the time to publication is reasonable (in 1994 the median time to acceptance was 102 (range 1-395) days, the median time to rejection was 40 (range 1-371) days, and the median time from receipt of manuscripts to publication was 247 (range 35-531) days) but there is room for further improvement.

There have been several other important developments in the last seven years. Firstly the journal changed size in 1992 and the new A4 format allowed for a more flexible and attractive layout. Secondly we changed the cover design, added a subtitle The fournal of Sexual Health, STDs and HIV, which I believe better describes the coverage of the journal, and placed the contents on the front cover. Finally, in common with many other biomedical journals, we have introduced structured abstracts.

I believe that I have achieved most of my objectives and that the journal is dynamic and healthy and that this is the ideal time to hand over the reins to a new editor with fresh ideas and objectives. I am sure that Dr Mohsen Shahmanesh a genitourinary physician with a distinguished academic career, who takes over as editor in January 1996 will fulfil the role admirably.

There are many people who have assisted me during my seven years as editor and I would like to thank them for their hard work and commitment and for making the position more enjoyable and challenging. I hope they will forgive me for not mentioning them all by name. There are a few people who deserve special attention. Firstly, my two assistant editors, Dr Chris Carne who has efficiently dealt with correspondence and book reviews, and was responsible for facilitating my move to Australia by acting as editor for a few months at the end of 1992, and Dr Chris Sonnex who has been responsible for compiling "Current Publications" our regular listing of relevant manuscripts published elsewhere. Secondly, Dr Kenneth Till our technical editor, whose quiet approach and efficient management have ensured that the journal has run smoothly. Finally my secretaries Paula Williams in London and Kylie McCarthy in Sydney and assistants Francisco Duque-Portugal and Caron Marks who between them kept the files, correspondence and the computer manuscript tracking system up to date. Francisco deserves special mention for helping to make my move from London to Sydney as seamless as possible. He was responsible for setting up our database and computer tracking system in Sydney and for overcoming numerous technical and logistic problems. Francisco died earlier this year and his humanity, warm sense of humour, and efficiency are sorely missed.

ADRIAN MINDEL Academic Unit of Sexual Health Medicine, Sydney Hospital, Sydney, Australia October 1995 